\title{
In vitro bioactivity evaluation of $\alpha$-calcium sulphate hemihydrate and bioactive glass composites for their potential use in bone regeneration
}

\author{
YANYAN ZHENG ${ }^{1, *}$, CHENGDONG XIONG ${ }^{2}$, DUJUAN ZHANG ${ }^{2}$ and LIFANG ZHANG ${ }^{2}$ \\ ${ }^{1}$ School of Basic Medical Sciences, North Sichuan Medical College, Nanchong 637000, People's Republic of China \\ ${ }^{2}$ Chengdu Institute of Organic Chemistry, Chinese Academy of Sciences, Chengdu 610041, People's Republic of China \\ *Author for correspondence (yanyzheng@163.com)
}

MS received 5 May 2017; accepted 18 July 2017; published online 4 April 2018

\begin{abstract}
To combine the self-setting property of $\alpha$-calcium sulphate hemihydrate ( $\alpha$-CSH) with the bioactive property of bioactive glass (BG), BG was added into $\alpha-\mathrm{CSH}$ to prepare $\alpha-\mathrm{CSH} / \mathrm{BG}$ composites. The in vitro bioactivity and cytocompatibility of the $\alpha-\mathrm{CSH} / \mathrm{BG}$ composites were assessed by soaking the composites in simulated body fluid (SBF) and co-culturing with the osteoblasts, respectively. Formation of a bone-like apatite layer on the composite surface was studied by X-ray diffraction (XRD), Fourier transform infrared spectrometry (FTIR), scanning electron microscopy (SEM) and energy-dispersive spectroscopy (EDS). Variations in ionic concentration and $\mathrm{pH}$ of the SBF solution were detected. The incorporation of BG into $\alpha-\mathrm{CSH}$, effectively compensated for the $\mathrm{pH}$ decrease caused by the dissolution of $\alpha$-CSH and the ion exchange. Osteoblast-like cells (MG63) were cultured on the samples, and the MTT results confirmed that the composites containing BG were more favourable for the proliferation of these cells. Hence, $\alpha-\mathrm{CSH} / \mathrm{BG}$ composites might have great potential for the use as a bone regeneration material.
\end{abstract}

Keywords. Bioactive glass; $\alpha$-calcium sulphate hemihydrate; composite; bioactivity; cytocompatibility.

\section{Introduction}

Calcium sulphate hemihydrates $\left(\mathrm{CaSO}_{4} \cdot 1 / 2 \mathrm{H}_{2} \mathrm{O}, \mathrm{CSH}\right)$, also known as plaster of Paris, was used for over 100 years to prepare materials for bone regeneration [1]. The plaster, especially $\alpha$-calcium sulphate hemihydrates $(\alpha-\mathrm{CSH})$, has gained more attention in orthopaedic and dental applications in recent years [2-4]. CSH as a substitute for bone grafting was investigated for clinical applications owing to its rapid setting capability in situ after filling the bone defect, quick and complete resorption, followed by new bone formation without eliciting a significant inflammatory response and excellent biocompatibility [4-6]. Additionally, CSH is relatively inexpensive, readily available, easy to use and can be easily moulded to fit defects of any size. The setting properties of CSH allow it to be applied in a pellet or slurry form, making it easy to handle in various situations [7]. However, CSH cannot bond chemically to bone tissue because of its poor bioactivity [7-9], which significantly hinders its clinical applications.

Since Hench and his co-workers [10] have first reported the preparation of bioactive glass (BG) in 1971, new strategies inspired by BG were employed by researchers to promote bone regeneration at defect sites $[11,12]$. When BG was implanted in vivo, a bone-like apatite layer with the ability to bond with living bone formed on its surface [13] This apatite layer is chemically and structurally analogous to the main mineral phase of bone. Collagen fibres reinforced the bone-like apatite, forming the interface bonding layer between BG and bone tissues. Thus, it is believed that the formation of a bioactive bone-like apatite layer on the BG surface is required for BG to chemically bond to living bone. The apatite layer that formed on the BG surface in vivo can also be evaluated in vitro using simulated body fluid (SBF) with ion concentrations nearly equal to those of human blood plasma [14]. However, several disadvantages of BG were recognized and reported, including its limited strength, poor ductility, poor mouldability and lowdegradation rate that prevents the in-growth of new bone tissue [15]. Hence, this material is often used in the form of granules.

Two of the major problems associated with using particulate materials are their handling properties and the migration of particles. $\alpha$-CSH was proposed as an effective binding and stabilizing agent for particulate materials [16]. In the present work, BG was introduced into $\alpha$-CSH to prepare $\alpha-\mathrm{CSH} / \mathrm{BG}$ composites, and the in vitro bioactivity and cytocompatibility of the composites were investigated. 


\section{Materials and methods}

\subsection{Material preparation}

Bioactive glass (BG) composed of $60 \% \mathrm{SiO}_{2}, 36 \% \mathrm{CaO}$ and $4 \% \mathrm{P}_{2} \mathrm{O}_{5}(\mathrm{~mol} \%)$ was prepared according to a previous report [17]. $\alpha-\mathrm{CSH}$ powder was synthesized as previously described [2]. Other agents all were of analytical grade.

\subsection{Preparation of the $\alpha-C S H / B G$ composites}

Composites of $\alpha-\mathrm{CSH} / \mathrm{BG}$ containing 5, 10 and 20\% BG in weight were prepared by wet mixing in a container with ethanol media. Next, the mixture of $\alpha-\mathrm{CSH}$ and BG powders was mixed with $0.9 \% \mathrm{NaCl}$ and an $\mathrm{L} / \mathrm{P}$ ratio (liquid to powder ratio) of $0.5 \mathrm{ml} \mathrm{g}^{-1}$. The mixture was stirred to form homogeneous paste within $1 \mathrm{~min}$, and transferred to stainless steel moulds with different dimensions $(4.7 \mathrm{~mm}$ diameter and $3.4 \mathrm{~mm}$ thickness for bioactivity and degradability tests, $10 \mathrm{~mm}$ diameter and $0.5 \mathrm{~mm}$ thickness for cytocompatibility tests), and then stored in a $100 \%$ humidity water bath at $37^{\circ} \mathrm{C}$ for 7 days.

\subsection{In vitro bioactivity}

The SBF was prepared using the procedure described by Kokubo et al [18]. The composites were soaked in SBF to evaluate their bioactivity. The dry composite disks immersed in the SBF were incubated at $37^{\circ} \mathrm{C}$ for 1,3 and 10 days with a W/V ratio (weight-to-volume ratio) of $0.048 \mathrm{~g} \mathrm{ml}^{-1}$.

After the predetermined immersion time, the samples were removed from SBF, gently rinsed with deionized water several times, and then air-dried in a desiccator. The morphological and structural variations in the composites before and after immersion in SBF were studied by X-ray diffraction (XRD, Philips X'Pert Pro) using CuK $\alpha$ radiation, Fourier transform infrared spectrometry (FTIR, Nicolet 200SXV) and scanning electron microscopy (SEM, S-520, Hitachi, Japan) coupled with energy-dispersive spectroscopy (EDS).

Sample solutions were monitored for calcium (Ca), phosphorus (P) and silicon ( $\mathrm{Si}$ ) concentrations as a function of soaking time. $\mathrm{Ca}, \mathrm{P}$ and $\mathrm{Si}$ concentrations were measured by inductively coupled plasma (ICP) optical emission spectrometry. The $\mathrm{pH}$ of the SBF was also synchronously determined using an acidometer.

\subsection{Mechanical testing of the composites}

After the predetermined immersion time, the dry samples were processed using the same method as previously described. An electromechanical universal testing machine (CMT6000, Sans, China) was employed to test the compressive strength of the samples at a compressive strain rate of $1 \mathrm{~mm} \mathrm{~min}{ }^{-1}$. The means with standard deviations of 10 parallel samples for each set of composites at different time points were calculated.

\subsection{In vitro degradation of the composites}

For evaluation of weight loss in vitro, the dry samples with an $\mathrm{L} / \mathrm{P}$ ratio of $0.5 \mathrm{ml} \mathrm{g}^{-1}$ immersed in the $\mathrm{SBF}$ were incubated at $37^{\circ} \mathrm{C}$ with a $\mathrm{W} / \mathrm{V}$ ratio of $0.048 \mathrm{~g} \mathrm{ml}^{-1}$. After the preselected time, the composites were dried at $70^{\circ} \mathrm{C}$ until they achieved a constant weight. The weight loss was expressed as a percentage of the initial weight.

\subsection{Cytocompatibility test}

MG63 cells were used to evaluate the cytocompatibility of the samples. The samples of pure $\alpha-\mathrm{CSH}$ and $\alpha-\mathrm{CSH} / \mathrm{BG}$ composites containing $20 \%$ BG were put in 24-well cell culture plates after sterilization with epoxy ethane. Subsequently, samples ( $n=3$ for each sample type and time point) were seeded with about $2.4 \times 10^{4}$ osteoblasts and incubated at $37^{\circ} \mathrm{C}$ in a humidified atmosphere of $5 \% \mathrm{CO}_{2}$. Twenty-four well tissue culture plates (TCPS) used as controls were treated with the same procedure. The medium was replaced with fresh medium every three days.

An MTT (3-(4,5-dimethylthiazol-2-yl)-2,5-diphenyl tetrazolium bromide) assay was used to evaluate in vitro cell viability $[19,20]$. The medium was removed after the cellloaded samples were incubated for 1, 3 and 6 days, and then the specimen was rinsed with phosphate-buffered saline (PBS) three times. Next, $1 \mathrm{ml}$ culture medium and $40 \mu \mathrm{l}$ MTT solution ( $5 \mathrm{mg} \mathrm{ml}^{-1}$ in PBS) were transferred into each well. After maintenance in an incubator at $37^{\circ} \mathrm{C}$ for $4 \mathrm{~h}$, the insoluble formazan crystals were dissolved in $420 \mu \mathrm{l}$ DMSO. Finally, the optical density of each well was measured using a microplate reader (Varioskan Flash 3001; Thermo, Marietta, $\mathrm{OH})$ at $595 \mathrm{~nm}$, after $100 \mu \mathrm{l}$ of solution was added into each well of a $96-$-well plate.

\section{Results}

\subsection{Variations in the composites after soaking in SBF}

The composite samples were immersed in SBF to evaluate their bioactivity and variations in the composites before and after soaking in SBF were studied by XRD, FTIR, SEM and EDS. Figure 1 displays the XRD diagrams of $\alpha-\mathrm{CSH}$ and $\alpha-\mathrm{CSH} / \mathrm{BG}$ before and after soaking in SBF for different periods, and the peaks indicating apatite formation are registered. The XRD patterns of pure $\alpha-\mathrm{CSH}$ (figure 1A) exhibited no clear visible changes before and after immersion. For the composites, however, diffraction peaks for apatite at $2 \theta=28.39,31.35$ and $32.88^{\circ}$ appeared (figure $1 \mathrm{~B}, \mathrm{C}$ and D), confirming that apatite was formed on the composites surface. The intensity of these characteristic peaks increased with increasing reaction time.

The FTIR spectra of $\alpha-\mathrm{CSH}$ and $\alpha-\mathrm{CSH} / \mathrm{BG}$ before and after immersion in SBF are presented in figure 2. As observed, 

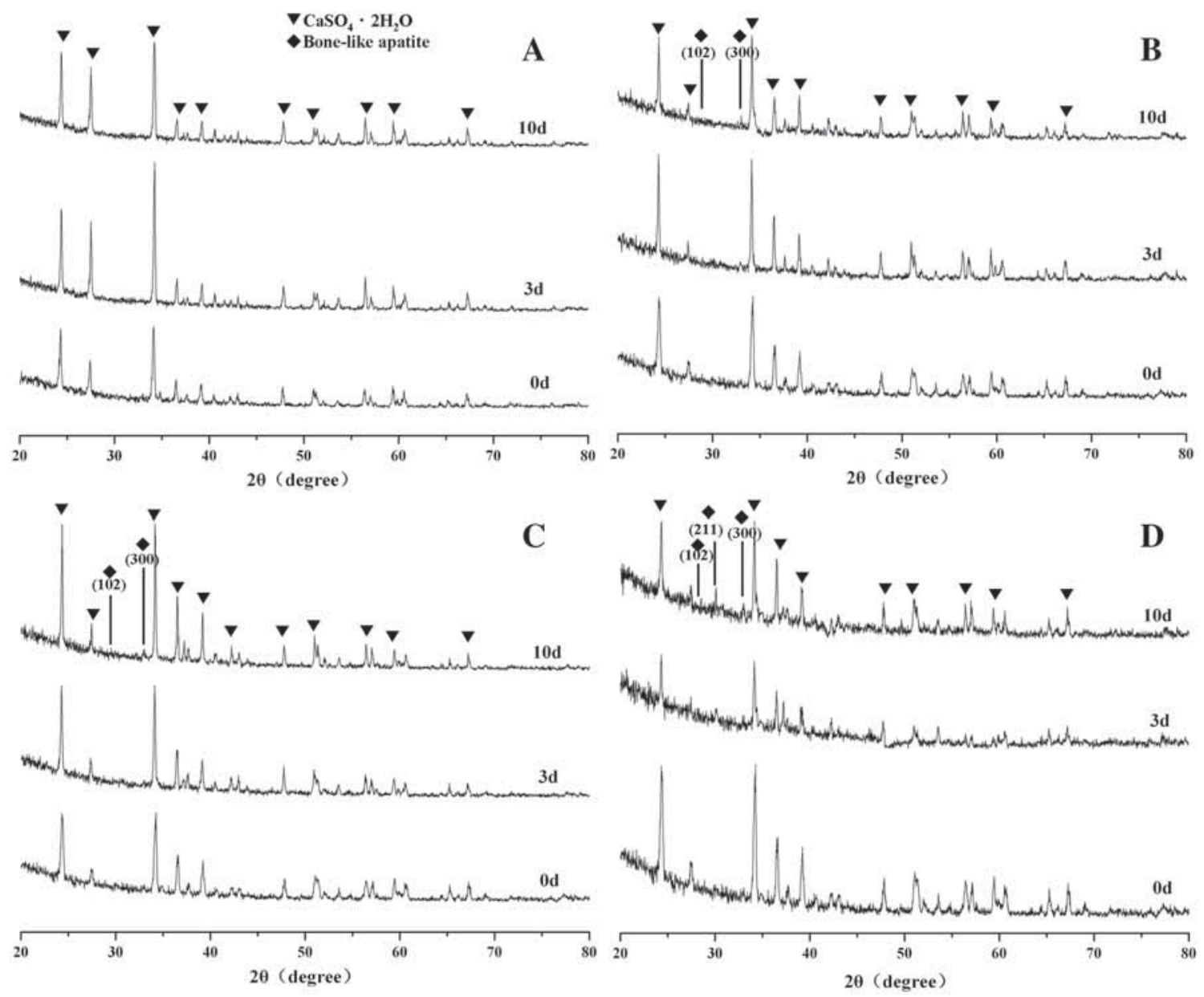

Figure 1. XRD patterns of the composites before and after immersion in SBF. (A), (B), (C) and (D) represent the $\alpha-\mathrm{CSH} / \mathrm{BG}$ composites containing $0,5,10$ and $20 \% \mathrm{BG}$, respectively.

after soaking the composites in SBF, the peak between 1455 and $1421 \mathrm{~cm}^{-1}$, which is a characteristic peak of the carbonate group [21], arises from the $\mathrm{C}-\mathrm{O}$ vibration (figure $2 \mathrm{~B}, \mathrm{C}$ and D). The absorption at $871 \mathrm{~cm}^{-1}$ was due to both $\mathrm{CO}_{3}^{2-}$ and $\mathrm{HPO}_{4}^{2-}$. The peak at $1030 \mathrm{~cm}^{-1}$ was mainly attributed to $\mathrm{PO}_{4}^{3-}[19,21]$. When the content of $\mathrm{BG}$ in the composites or the soaking time increased, the intensity of these peaks increased. However, the FTIR spectrum of $\alpha$-CSH did not exhibit distinct changes before and after immersion in SBF (figure 2A). The FTIR spectrum of the composites showed that the precipitate deposited on the composites after soaking was carbonate-containing apatite. Thus, the precipitate formed on $\alpha-\mathrm{CSH} / \mathrm{BG}$ surface after soaking in SBF is bonelike apatite because biologic apatite is carbonate-containing apatite.

Figure 3 presents the SEM images of $\alpha-\mathrm{CSH}$ and $\alpha$ CSH/BG after immersion in SBF for 0, 3 and 10 days. No apparent changes on the surfaces of pure $\alpha$-CSH were visible even after 10 days (figure $3 \mathrm{~A}$ ). However, precipitates were observed on the composite surfaces (figure $3 \mathrm{~B}, \mathrm{C}$ and $\mathrm{D}$ ), and the composite with $20 \%$ BG was covered with a layer of precipitate (figure 3D). The EDS analysis of the chemical composition of the sediment again confirmed that the precipitate that formed on the composite surface after soaking in SBF was bone-like apatite (figure 3E).

\subsection{Variations in $S B F$}

Changes ( $\mathrm{pH}, \mathrm{Ca}, \mathrm{P}$ and $\mathrm{Si}$ ) in $\mathrm{SBF}$ occurred during the in vitro bioactivity test for $\alpha-\mathrm{CSH}$ and $\alpha-\mathrm{CSH} / \mathrm{BG}$ composites with increasing soaking time (figure 4). As shown in figure 4A, the concentration of $\mathrm{Ca}$ increased after the composite was immersed in SBF for 1 day, a slight decline occurred at 2 days, and then, a maximum was reached at 3 days that remained almost unchanged. The $\mathrm{Ca}$ concentration of SBF with pure $\alpha-\mathrm{CSH}$ increased continuously until reaching a maximum at 7 days and then remaining the same. As immersion time in SBF increased, the concentration of phosphorous decreased (figure 4B), indicating that the composite surfaces were being covered by an apatite layer. Figure $4 \mathrm{C}$ illustrates that the concentration of $\mathrm{Si}$ increases first, reaches a maximum at 3 days, 


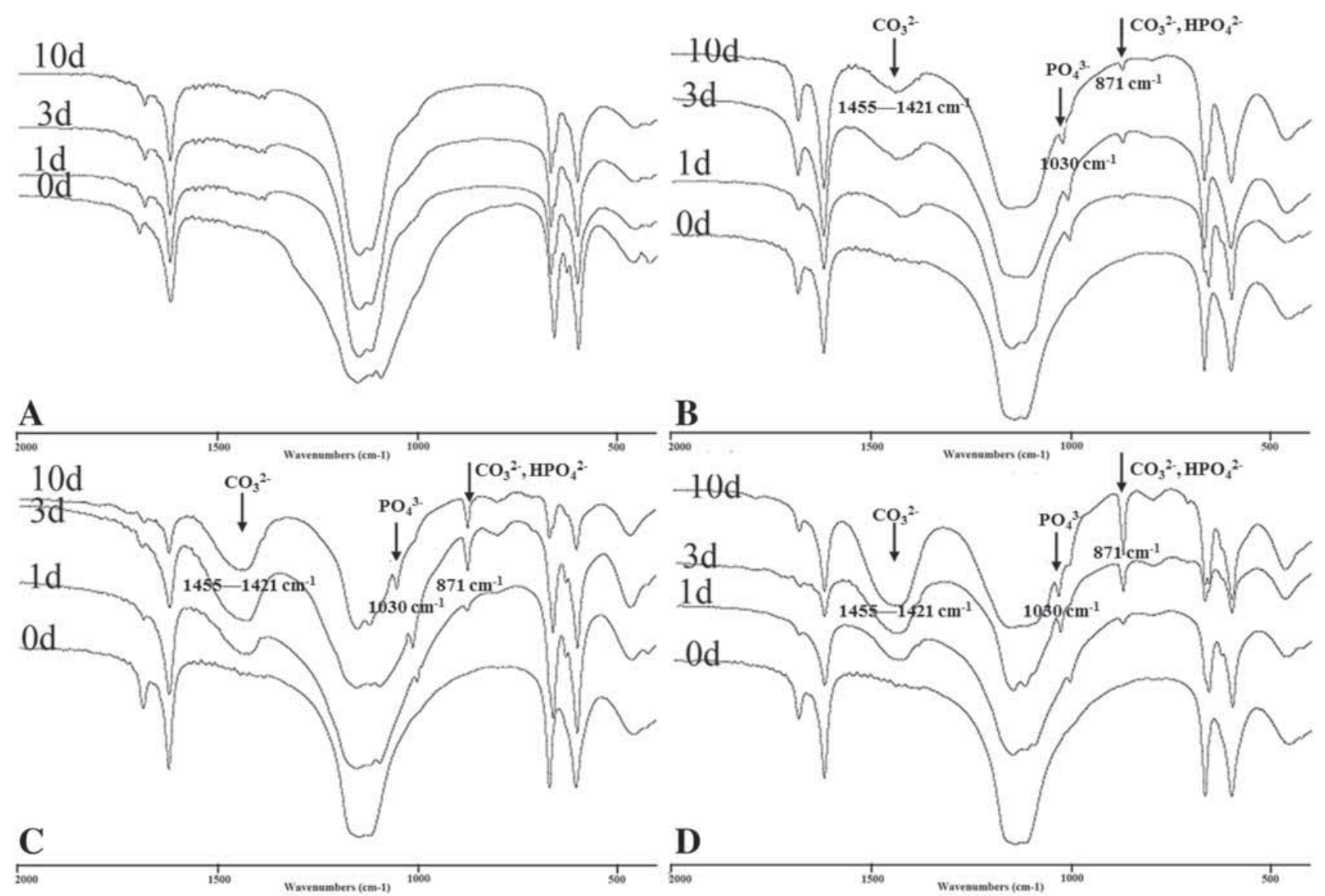

Figure 2. FTIR spectrum of the composites before and after soaking in SBF. (A), (B), (C) and (D) represent the $\alpha-\mathrm{CSH} / \mathrm{BG}$ composites containing $0,5,10$ and $20 \% \mathrm{BG}$, respectively.

and then, remains almost unchanged. Figure $4 \mathrm{~d}$ shows that the $\mathrm{pH}$ value of SBF containing $\alpha$-CSH/BGs composite samples increased from 7.40 to 8.15 after incubating for 14 days, while the $\mathrm{pH}$ of SBF with $\alpha$-CSH decreased from 7.40 to 6.95 .

The compressive properties of the composites after immersion in SBF for different durations are shown in figure 5. The addition of a small amount of BG enhanced the compressive strength of the composites, and the compressive strength of the composites decreased with increasing immersion time. As shown, there was no remarkable difference between the compressive strength of composites containing 10 and 5\% $\mathrm{BG}$. The compressive strength of the composites containing 10 and $5 \%$ BG was improved compared with that of pure $\alpha-\mathrm{CSH}$. This improvement could be attributed to the fact that BG particles tend to fill the micropores between the CSH crystals to reduce the microporosity of the paste [1].

\subsection{In vitro degradation}

Figure 6 exhibits the mass loss of the composites after immersion in SBF for different durations. As shown, pure
$\alpha$-CSH degraded rapidly in SBF. The degradation rates of the composites with different ratios of BG were similar because the degradation of the composite is mainly attributed to the degradation of the CSH. The weight of the composites decreased after immersion in SBF for 7 days and then increased due to the formation of a bone-like apatite layer on its surfaces. However, the weight of pure $\alpha$-CSH decreased initially, but was maintained after immersion in SBF for 15 days.

\subsection{In vitro cytocompatibility}

To quantitatively assess the cell viability of the composite, cell proliferation on the composite was evaluated by MTT assay after 1, 3 and 6 days of culture. As shown in figure 7, after 3 and 6 days, the proliferation activity of MG63 cells cultured on the $\alpha-\mathrm{CSH} / \mathrm{BG}$ composites containing BG was significantly different from that on the pure $\alpha-\mathrm{CSH}$ and TCPS. The results demonstrated that the $\alpha-\mathrm{CSH} / \mathrm{BG}$ composites had superior cytocompatibility. 

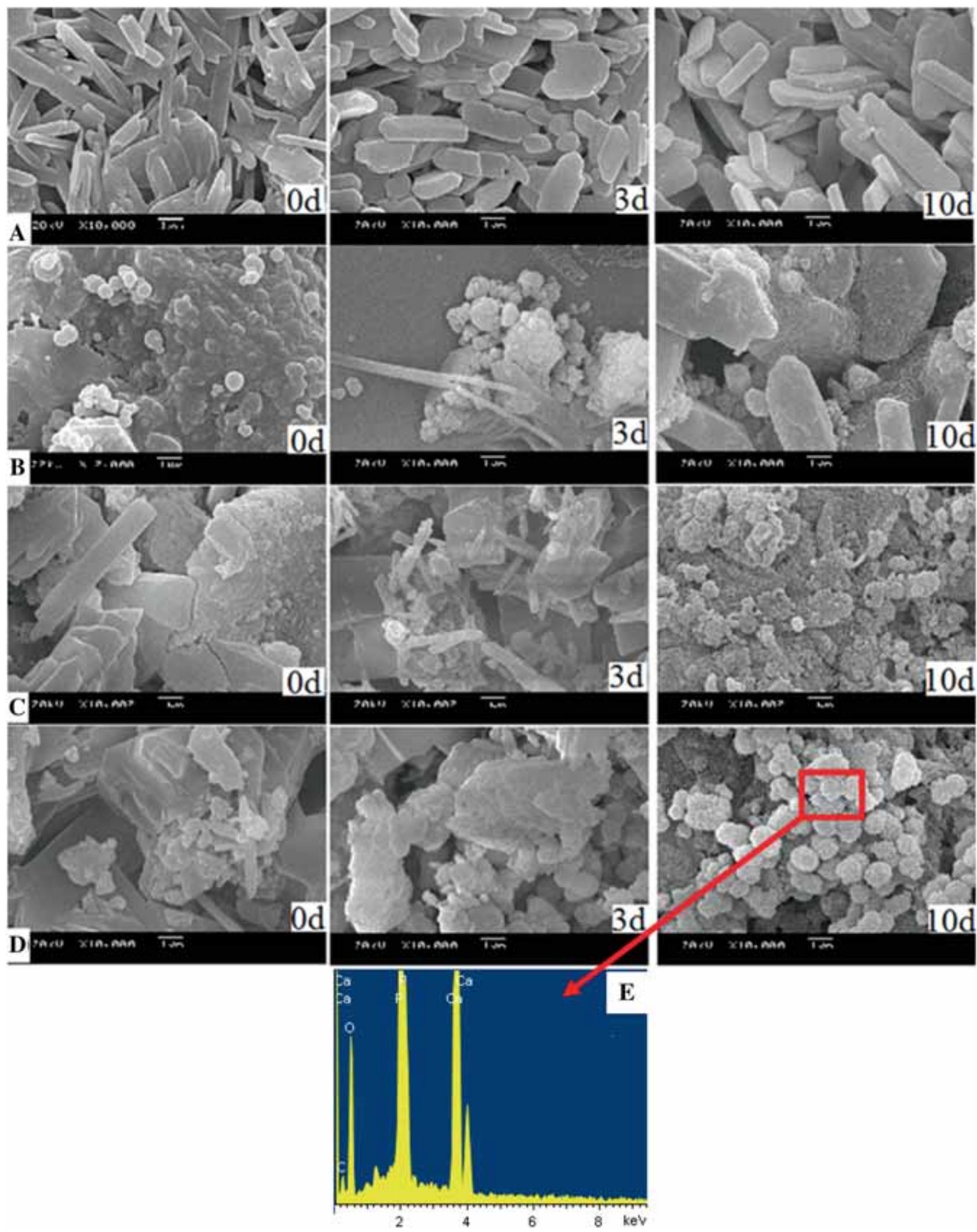

Figure 3. SEM images of the composites. (A), (B), (C) and (D) represent the $\alpha-\mathrm{CSH} / \mathrm{BG}$ composites containing $0,5,10$ and $20 \%$ BG, respectively, after soaking in SBF for 0, 3 and 10 days. (E) EDS spectra of the precipitates was formed on the composite containing $20 \%$ BG. 

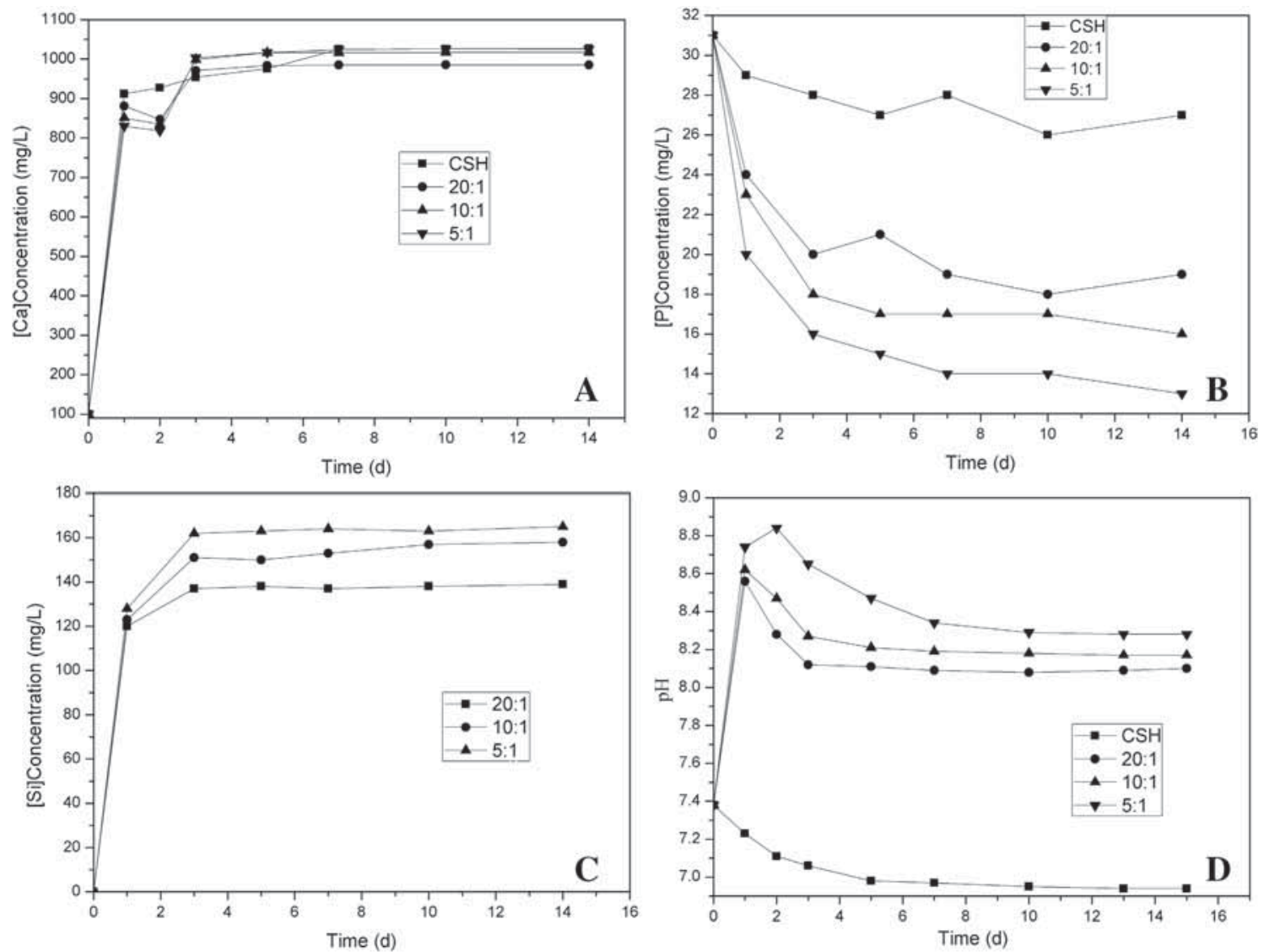

Figure 4. Changes in SBF induced by the immersion of the composites as a function of soaking time. Changes in (A) Ca ionic concentration, (B) P ionic concentration, (C) Si ionic concentration and (D) $\mathrm{pH}$.

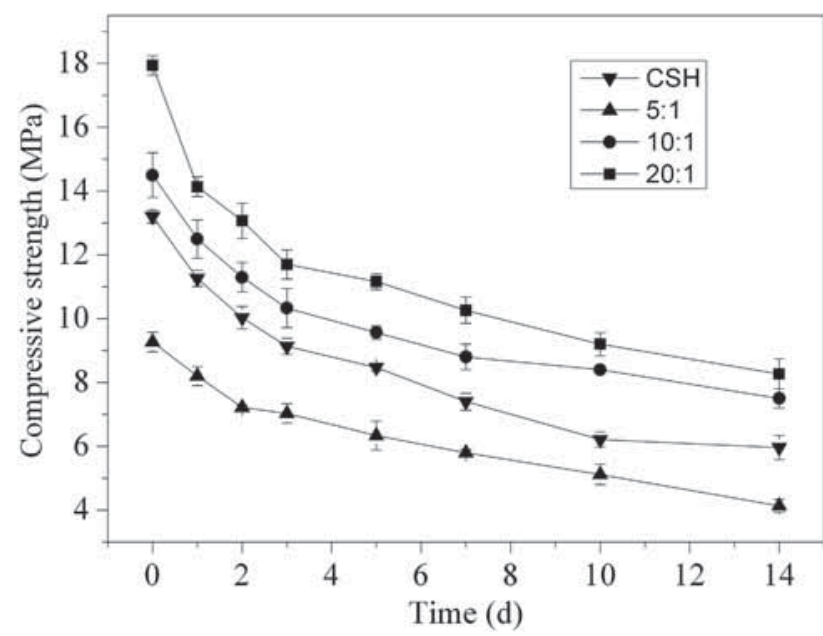

Figure 5. Compressive strength of the composites with respect to soaking time in SBF.

\section{Discussion}

Numerous in vitro and in vivo studies have confirmed that pure $\mathrm{CSH}$ cannot bond chemically to osseous tissues because

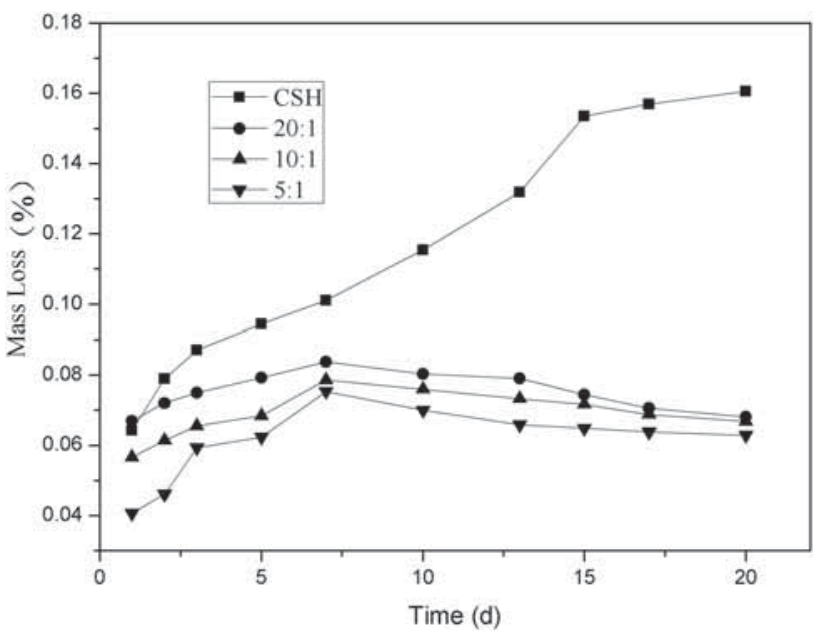

Figure 6. Degradation of $\alpha-\mathrm{CSH} / \mathrm{BG}$ composite with different contents of BG after soaking in SBF for various durations.

of its poor bioactivity [1,7-9]. Bone-like apatite does not form on the surface of pure CSH after immersion in SBF, and the present study also confirmed that CSH lacks bioactivity. The combined results of XRD, FTIR, SEM and EDS indicated 


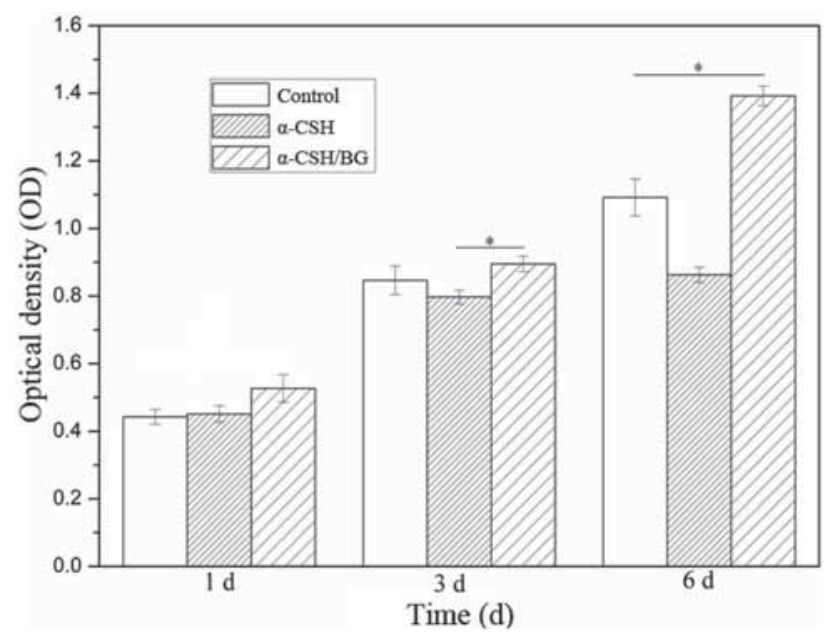

Figure 7. Cell proliferation of MG63 osteoblasts cultured on TCPS, pure $\alpha-\mathrm{CSH}$ and $\alpha$-CSH/BG composite containing $20 \%$ BG for 1,3 and 6 days. Asterisk represents a statistically significant difference in the OD value of the $\alpha-\mathrm{CSH} / \mathrm{BG}$ composite compared to the $\alpha-\mathrm{CSH}$ and control $(P<0.05$, Student's $t$-test $)$.

that the $\alpha-\mathrm{CSH} / \mathrm{BG}$ composites can induce bone-like apatite deposition on their surfaces within a day, suggesting that the composites show good bioactivity. BG bonds chemically to bone tissues by the formation of a bone-like apatite layer on its surface [15]. Thus, the in vitro bioactivity of the $\alpha-\mathrm{CSH} / \mathrm{BG}$ composites could be ascribed to the introduction of BG into the composites, and the content of BG has a strong effect on the formation of bone-like apatite. For all the composites, the apatite precipitates were observed to be induced initially as an amorphous phase, and then, the initial amorphous structure was converted into a crystalline phase with prolonged soaking time. Our results illustrated that the introduction of BG into non-bioactive $\alpha$-CSH material could result in a composite material with adjustable bioactivity.

Our results indicated that the underlying mechanism of formation of bone-like apatite on the $\alpha-\mathrm{CSH} / \mathrm{BG}$ composites surfaces was similar to that of BG [13]. First, the exchange of ions between the $\mathrm{Ca}^{2+}$ and $\mathrm{Na}^{+}$from the $\mathrm{BG}$ and the $\mathrm{H}_{3} \mathrm{O}^{+}$ from the SBF solution, results in the formation of $\mathrm{Si}-\mathrm{OH}$ and increase in the $\mathrm{pH}$ of the SBF. Next, the silica network is attacked and the dissolution of silica occurs, leading to more $\mathrm{Si}-\mathrm{OH}$ formation and $\mathrm{Si}(\mathrm{OH})_{4}$ release. Subsequently, condensation and polymerization reactions of the surface Si-OH form a negative silica-rich gel layer. Finally, the positively charged $\mathrm{Ca}^{2+}$ is attracted to the composite surface, leading to the formation of bone-like apatite. As for the $\alpha$-CSH/BG composite containing $20 \% \mathrm{BG}$, the number of negative sites was so high that ions could homogeneously disperse within the composite, providing more nucleation sites for bone-like apatite deposition, and thus, a uniform apatite layer covered the entire composite surface (figure 3D).

Pure $\alpha-\mathrm{CSH}$ and $\alpha-\mathrm{CSH} / \mathrm{BG}$ composites exhibited different cytocompatibilities. Compared to pure $\alpha-\mathrm{CSH}$, the composites offered a more beneficial environment for cell proliferation. This may be due to the local $\mathrm{pH}$ variation. As shown in figure $4 \mathrm{D}$, the changes in $\mathrm{pH}$ indicated that the $\alpha-\mathrm{CSH} / \mathrm{BG}$ composites could compensate for the low $\mathrm{pH}$ of SBF solution. Therefore, the BG in the composites showed a compensation effect in the acidic $\mathrm{SBF}$, and the mechanism was the neutralization ability of the alkaline ions released from the BG after soaking in SBF. Since relatively low $\mathrm{pH}$ environment tend to suppress cell proliferation [22], pure $\alpha$-CSH showed less cytocompatibility than $\alpha$-CSH/BG composites. Additionally, previous studies have shown that cell proliferation can be stimulated by the dissolution extracts of bioactive glasses and ceramics [1]. Thus, the ionic dissolution products in the medium from the composites may also provide a beneficial stimulus for cell proliferation. In summary, our results indicate that the $\alpha-\mathrm{CSH} / \mathrm{BG}$ composites possess superior in vitro bioactivity and cytocompatibility, and have great potential for use as bone regeneration materials.

\section{Conclusions}

In our study, bioactive composites were successfully prepared by introducing BG into $\alpha-\mathrm{CSH}$. Bone-like apatite formed on the composite surfaces after immersion in SBF, indicating that the composites had excellent in vitro bioactivity. The MTT assay demonstrated the excellent cytocompatibility of the composites containing BG. The compressive strength of the composites improved with the addition of $\mathrm{BG}$, and $\mathrm{BG}$ also acted as a pH-compensating agent for the $\alpha-\mathrm{CSH} / \mathrm{BG}$ composite bone defect fillers. Taken together, the results show that $\alpha-\mathrm{CSH} / \mathrm{BG}$ composites have great potential for use as bone regeneration materials.

\section{Acknowledgements}

This work was supported financially by the Doctoral Program of North Sichuan Medical College (No. CBY16-QD-02), the North Sichuan Medical College Scientific Research and Development Projects (No. CBY16-A-ZD02), and the key project of 'Western Light' Foundation of Chinese Academy of Sciences.

\section{References}

[1] Huan Z and Chang J 2007 Acta Biomater. 3952

[2] Keya M, Feihu Z, Fuzai C, Jiangtao L, Xijun H, Peng L et al 2013 Bio-Med. Mater. Eng. 23197

[3] Pecora G, Andreana S, Margarone III J E, Covani U and Sottosanti J S 1997 Or. Surg. Or. Med. Or. Pathol. 84424

[4] Chen J, Gao J, Yin H, Liu F, Wang A, Zhu Y et al 2013 Mater. Sci. Eng. C 333256 
[5] Hughes E, Yanni T, Jamshidi P and Grover L M 2015 Adv. Appl. Ceram. 11465

[6] Thomas M V and Puleo D A 2009 J. Biomed. Mater. Res. Part B 88597

[7] Stubbs D, Deakin M, Chapman-Sheath P, Bruce W, Debes J, Gillies R et al 2004 Biomaterials 255037

[8] Orsini G, Ricci J, Scarano A, Pecora G, Petrone G, Iezzi G et al 2004 J. Biomed. Mater. Res. Part B 68B 199

[9] Cabanas M V, Rodriguez-Lorenzo L M and Vallet-Regi M 2002 Chem. Mater. 143550

[10] Hench L L, Splinter R J, Allen W and Greenlee T $1971 \mathrm{~J}$. Biomed. Mater. Res. 5117

[11] Zhang D J, Zhang L F, Xiong Z C, Bai W and Xiong C D 2009 J. Mater. Sci. Mater. Med. 201971

[12] Bellucci D, Sola A and Cannillo V 2014 Biomed. Mater. 9 015005
[13] Jones J R2013 Acta Biomater. 94457

[14] Kokubo T and Yamaguchi S 2016 Acta Biomater. 4416

[15] Kaur G, Pandey O P, Singh K, Homa D, Scott B and Pickrell G 2014 J. Biomed. Mater. Res. Part A 102254

[16] Snyders Jr R V, Eppley B L, Krukowski M and Delfino J J 1993 J. Oral Maxil. Surg. $\mathbf{5 1} 517$

[17] Ramila A, Balas F and Vallet-Regi M 2002 Chem. Mater. 14 542

[18] Kokubo T and Takadama H 2006 Biomaterials 272907

[19] Zheng Y, Xiong C, Zhang S, Li X and Zhang L 2015 Mater. Sci. Eng. C 55512

[20] Zheng Y, Xiong C, Li X and Zhang L 2014 Appl. Surf. Sci. 320 93

[21] Zheng Y, Xiong C and Zhang L 2014 Mater. Lett. 126147

[22] Shen Y, Liu W, Lin K, Pan H, Darvell B W, Peng S et al 2011 Langmuir 272701 